\title{
Semantic dispositionalism without exceptions
}

\author{
Arvid Båve ${ }^{1}$
}

Published online: 10 April 2019

(C) The Author(s) 2019

\begin{abstract}
Semantic Dispositionalism is roughly the view that meaning a certain thing by a word, or possessing a certain concept, consists in being disposed to do something, e.g., infer a certain way. Its main problem is that it seems to have so many and disparate exceptions. People can fail to infer as required due to lack of logical acumen, intoxication, confusion, deviant theories, neural malfunctioning, and so on. I present a theory stating possession conditions of concepts that are counterfactuals, rather than disposition attributions, but which is otherwise similar to inferentialist versions of dispositionalism. I argue that it can handle all the exceptions discussed in the literature without recourse to ceteris paribus clauses. Psychological exceptions are handled by suitably undemanding requirements (unlike that of giving the sum of any two numbers) and by setting the following two preconditions upon someone's making the inference: that she considers the inference and has no motivating reason against it. The non-psychological exceptions, i.e., cases of neural malfunctioning, are handled by requiring that the counterfactuals be true sufficiently often during the relevant interval. I argue that this accommodates some important intuitions about concept possession, in particular, the intuition that concept possession is vague along a certain dimension.
\end{abstract}

Keywords Dispositionalism · Kripke - Wittgenstein · Kripkenstein · Dispositions · Meaning · Concepts · Inferentialism - Conceptual role semantics · Peacocke · Ceteris paribus $\cdot$ Naturalism $\cdot$ Boghossian $\cdot$ Horwich

I will here put forward and defend a new variant of Semantic Dispositionalism, the view that someone's meaning something by a word, possessing a certain concept,

Arvid Båve

1 Stockholm, Sweden 
etc., consists in their being disposed to do something, e.g., infer a certain way. Actually, I will propose that such semantic notions are analysed rather in terms of counterfactual conditionals, but this is still very much in the spirit of standard dispositionalism. We may distinguish between Strict Semantic Dispositionalism, which takes semantic claims to be analysable as proper disposition attributions, and Broad Semantic Dispositionalism, which includes my "conditional” variant.

Why treat my account as a form of "dispositionalism" at all? Because for most intents and purposes of the debate about Semantic Dispositionalism, the difference is insignificant. Kripke would not have taken my conditional account as interestingly different from the strict variety he was discussing. Also, Barbara Vetter has argued convincingly that philosophers' use of "disposition" is technical, and tied to a "conditional conception" of dispositions (2014: 147f.). In other words, they simply mean by "disposition" something that can be captured by a conditional. In any case, whenever the difference does become significant, we can easily revert to the disambiguation just made, so no confusion should arise. ${ }^{1}$

I will present no positive argument for "the very idea" of Semantic Dispositionalism $^{2}$ but rather propose a positive account and argue that it steers clear of the exceptions (or counterexamples) found in the literature, which target extant forms of Semantic Dispositionalism. The account only concerns the simple case of conjunction, and I will sidestep the vast question how other meanings/concepts should be handled, as this simple case involves enough trouble for one paper.

There is much else discussed in the literature on Semantic Dispositionalism that I will forego. The concept of rule following will not be touched upon. Rather, I discuss whether semantic claims can be analysed as counterfactuals, staying neutral on whether meaning something amounts to rule following, or whether rule following can be analysed in terms of counterfactuals. I similarly "cut out the middle man" with regard to dispositions: I don't discuss whether semantic properties are constituted by dispositions, nor whether disposition claims can be analysed as counterfactuals. I merely discuss whether semantic claims can be analysed as counterfactuals. This seems to me a recommending feature of the theory, as it thereby shuns two controversial and obscure notions in favour of counterfactuals, which are comparatively well understood. Given the radical disagreements about the nature of dispositions in the contemporary debate, it seems inadvisable to appeal to them at all in a theory that aims to explain something other than dispositions.

\footnotetext{
${ }^{1}$ Gundersen (2002) and Choi (2008) argue that attributions of canonical dispositions, like " $x$ is disposed to break if struck", should be analysed as simple counterfactuals. If they are right and my account is true, then, by the transitivity of equivalence, we can infer a form of Strict Semantic Dispositionalism, namely, one which takes semantic claims to be equivalent with ascriptions of canonical dispositions. Note, however, that this form of dispositionalism does not commit us to saying that semantic properties are conventional dispositions, like fragility. In fact, both Gundersen and Choi deny that conventional dispositions can be analysed as canonical dispositions.

Further competing analyses of dispositions include Crane (1996), Lewis (1997), Mumford (1998), Heil (2003), Fara (2005), Manley and Wasserman (2008), Choi (2008), Steinberg (2010) and Vetter (2014).

2 Such arguments can be found in Boghossian (2003) and Horwich (2005).
} 
Finally, I also ignore large parts of the literature that concerns the specific dispositionalist analysis of meaning plus by "+", discussed by Kripke. This omission is motivated by the claim, argued in Sect. 3, that that specific analysis is particularly unpromising, and therefore distracts from the more interesting questions about Semantic Dispositionalism.

The focus of the paper, then, is on a new, broadly dispositionalist theory of certain semantic properties (of concept possession, in fact), and how it handles the exceptions that threaten other such theories. These exceptions are both many and disparate. For instance, someone might fail to manifest such a disposition because of their finitude, or due to ineptitude, inattention, intoxication, confusion, fatigue, belief in deviant philosophical theories or logics, or neural malfunctioning. Each of these exceptions is a problem in its own right, but, as I explain in Sect. 2, they also collectively constitute a problem which is more than the sum of its parts, and which derives precisely from the fact that they seem precisely so many and disparate. Overcoming these difficulties is the main purpose of this paper.

I will defend a broadly "inferentialist" theory about possessing the concept AND, on which possessing this concept consists in inferring in accordance with certain rules under certain counterfactual circumstances. My main novel points will be

(1) that the presumed number and disparity of exceptions to broadly dispositionalist analyses has been exaggerated,

(2) that all psychological exceptions can be dealt with by setting a suitably undemanding requirement (unlike the requirement of giving the sum of any pair of numbers), and including merely two stimulus conditions, namely, of considering the relevant inference, and of having no motivating reason against making it,

(3) that non-psychological exceptions, particularly, exceptions due to neural malfunction, are to be handled by the condition that the relevant counterfactuals be true sufficiently often (during the relevant interval).

Section 1 describes the relevant objections against Semantic Dispositionalism more thoroughly. Section 2 offers some preliminaries, states the first version of the theory, and makes some general points about it. Sections 3 and 4 deal respectively with the preconditions of considering inferences and of having no motivating reason against making an inference. Section 5 locates (the first version of) my view in dialectical space, and Sect. 6 proposes a modification of the theory, intended to handle neural exceptions.

\section{The problems of exceptions}

The debate about Semantic Dispositionalism has its roots in the specifically behaviourist dispositionalist ideas of the 1940s, but intensified considerably with Kripke's (1982) discussion, which will be our starting point. The dispositionalist claim at the focus of his discussion - call it Kripke's Dispositionalism-is that "to mean addition by ' + ' is to be disposed, when asked for any sum ' $x+y$ ', to give the 
sum of $x$ and $y$ as the answer" (1982: 22). As Kripke makes clear, this is not to be understood behaviouristically. There are plenty of well-known and decisive objections against behaviouristic analyses of mental or semantic claims, but Kripke's more interesting objections target mentalist forms of dispositionalism, featuring mental notions like belief.

I will here focus only on arguments against dispositionalism consisting of alleged exceptions to dispositionalist analyses. ${ }^{3}$ The two main arguments of this kind are,

Error: We are prone to make mistakes and thus not disposed to always give the sum of any two numbers.

Finitude: Due to our finite nature, we cannot conceive of very large numbers, so we are not disposed to give the sum of such numbers.

In the ensuing debate, another problem for dispositionalism has emerged, raised by the sheer number and disparity of circumstances that may prevent a given disposition to be manifested. Aside from exceptions relating to error and finitude, someone may also fail to manifest the relevant disposition due to:

Deviant (philosophical) theories or logics: they have philosophical or other theoretical reasons against believing or inferring so and so (cf. Williamson 2007: Ch. 4).

Reasoned change in view: where the relevant disposition is to make a simple inference, one might fail to manifest it because one disbelieves the conclusion (cf. Harman 1986: 1ff.; Besson 2012).

Dysfunctional states: they are confused, inattentive, tired, stressed, distracted, or under the influence of drugs (see, e.g., Azzouni 2017: Ch. 2).

Neural malfunction (noise, disturbance, etc.): in this type of case, there is no psychological explanation of why the person fails to manifest the disposition, i.e., no explanation featuring psychological concepts like belief, perception, desire, etc. The explanation is rather purely physical (neural), consisting, e.g., in a neuron not firing in spite of receiving the right kind of input, or some neural factor blocking the manifestation of a disposition.

Opponents of Semantic Dispositionalism often provide a list like this, and then exclaim, "And so on!", implying that the list goes on for long, or even indefinitely. However, I have not found any particularly long list of exceptions anywhere in the literature, and will argue that the impression of a hopelessly wide range of exceptions is illusory.

\footnotetext{
${ }^{3}$ I will thus ignore the so-called arguments from normativity and extension-determination. It should be noted, however, that some philosophers more or less identify these arguments with the "problem of Error" [see Kripke (1982: 24), Martin and Heil (1998: 284ff.) and Handfield and Bird (2008: 286)]. But there are arguments worthy of these labels that go beyond the problem of Error. For instance, it could be argued that since meaning claims analytically or a priori entail normative claims, and disposition attributions (or counterfactuals) don't, the latter cannot be used to analyse the former. Similarly, it can be argued that since meaning claims directly entail extension attributions and disposition claims do not, the latter cannot be used to analyse the former. I take both of these arguments to have been persuasively rebutted [see, e.g., Glüer and Wikforss $(2009,2018)$ on the former and Horwich (1998: Ch. 10, 2005: Ch. $3)$ on the latter].
} 
The illusion may be due partly to a superficial similarity with the main obstacle to behaviourist analyses of mental states, and with conditional analyses of such "conventional" dispositional properties as brittleness. For instance, the behaviourist idea of identifying belief with a disposition to utter or assent to a sentence seems implausible in view of the sheer number and disparity of factors that may inhibit this behaviour: shyness, dishonesty, aphasia, defiance, inattention, ... and so on! Simple conditional analyses of properties like brittleness seem similarly beset by an indefinite number of exceptions, like the notorious finks, masks, etc. [see Choi and Fara (2018) for an overview]. But mentalist versions of Semantic Dispositionalism are different, or so I will argue.

Let us get clearer on what exactly the problem of the "many and disparate exceptions" is supposed to be. I take it to consist in a dilemma, both horns of which seem untenable. The first option is to deal with the exceptions by explicitly saying of each of them that its absence is a precondition for the manifestation of the disposition. But, the objection goes, considering the number and disparity of possible inhibiting factors, it seems that this will require an intolerably complex, gerrymandered, and possibly even infinite analysis.

The second option is to cover all exceptions with a "ceteris paribus" clause, like "barring inhibiting factors", "in ideal circumstances", or "in normal circumstances". But it seems difficult to explicate these hedges without making ceteris paribus laws come out false or trivial. ${ }^{4}$ In response, it has been argued that there must be some way of making such laws non-vacuously true, given their prominent role in science [see, e.g., Fodor (1983, 1991), and Steinberg (2010: §4)]. As against this line of reasoning, it has been argued that ceteris paribus hedges may be admissible for scientific purposes but not for those of Semantic Dispositionalism [see Kusch (2005) and, for a reply, Cheng (2009)].

\section{Toward an improved form of Semantic Dispositionalism}

Although the account I propose here is like the first horn of the above dilemma in that it eschews ceteris paribus clauses, it is not aptly described as a theory which "explicitly rules out each exception". Rather, it contains only two qualifications, and I will argue that they take care of all psychological exceptions (albeit not nonpsychological, "neural" exceptions, which are handled by a modification of the theory, presented in Sect. 6). A benefit of this theory is that it avoids the commitment to analysing ceteris paribus hedges, and thus runs no risk of trivialization.

The theory I will propose is quite different from Kripke's. In my view, the debate has suffered seriously from the assumption that Semantic Dispositionalism stands or falls with his very optional, very specific, and arguably very implausible dispositionalist analysis of meaning plus. In my view, that analysis is simply

\footnotetext{
${ }^{4}$ For an overview, see Reutlinger and Hüttemann (2017: §§4-5). See also Fodor (1983, 1990, 1991), Boghossian (1989: 537ff.), Kusch (2005, 2006), Tennant (1997, §4.7), Miller (1997: 181ff.), Pettit (1999), Pietroski and Rey (1995), Cheng (2009), Podlaskowski and Jones (2012) and Podlaskowski (2012).
} 
refuted by the arguments from Error and Finitude. It is as implausible as taking meaning prime to consist in a disposition to tell, of each number, whether it is prime. Meaning prime is more reasonably identified with a disposition to accept something obvious, which can be seen as a definition of "prime", and similarly for meaning plus by "+".

In line with this reasoning, Christopher Peacocke has proposed that possessing the concept PLUS consists in finding primitively compelling the Peano axioms containing "+" (1992: 134ff.). I find that particular proposal psychologically unrealistic, but the general idea remains sound: meaning something must consist in a disposition to accept something obvious and definitional. ${ }^{5}$ More generally, the relevant dispositions much be relatively undemanding, if the theory is not to succumb to the problem of Error. ${ }^{6}$

I will henceforth discuss the example of conjunction rather than addition, because I take the latter to involve complications with no relevance for my main message. I will also assume the neo-Gricean view that meaning something by an expression really consists of two separate things: possessing the relevant concept, and using the expression to express that concept [see, e.g., Davis (2003) for a detailed theory of this kind]. These two matters require separate accounts, and the dispositionalist view I will propose concerns only concept possession. It is obvious that, in a choice between possessing a concept and using a certain expression to express it, the former is more reasonably taken as the target of the debates about Semantic Dispositionalism. (Despite this difference between my account and Kripke's Dispositionalism, much of what I will have to say will apply also to dispositionalist accounts of "meaning $x$ by $e$ ".),

It has been independently argued by Peacocke (1992) that concepts can be individuated by their possession conditions. Appropriating Peacocke's "(A)-form individuations" and modifying them in accordance with the points above, my reductions will be roughly of the form,

(F) $x$ possesses $C$ (e.g., AND) iff, for some concept $c$, if $x$ were to ..., then $x$ would 一,

where the variable " $c$ " will occur in at least one of the spaces "..." and "—". While the analysandum in (F) is roughly that of Peacocke's concept individuations, the kind of analysans I shall propose differs importantly from his (and I will argue at length below that mine is preferable).

\footnotetext{
5 A more plausible candidate might be the inference from "There are $m F$ s and $n G$ s" and "No $F$ is a $G$ " to "There are $m+n$ things that are $F$ or $G$ ".

6 The problem of Error arguably also refutes the crude, dispositionalist idea that possessing the concept HORSE consists in a disposition to apply it to all and only horses. Possessing HORSE is more plausibly identified with a disposition to apply the concept in response to certain perceptions. A promising proposal is that the relevant perceptions can be adequately categorized as those belonging to a certain nonconceptual, perceptual similarity space, as defined, e.g., in Gauker (2011: Chs. 5-6). Many concepts will probably be associated rather with a cluster of dispositions, e.g., concepts of artefacts, which are associated both with shape recognition and beliefs about function.
} 
Finally, I will need some way of quantifying over propositions that are subpropositions in logically complex propositions. To this end, I will stipulate that the function $f$ takes dyadic propositional-operator concepts, like the concept AND, and pairs of propositions to the relevant logically complex proposition. Thus, the proposition that snow is white and grass is green $=f(\mathrm{AND}$, that snow is white, that grass is green), and so on [see Båve (forthcoming) for details].

The first version of the account of the concept AND that I'll defend now reads:

(D) $x$ possesses AND just in case, for some concept $c$,

(i) for every proposition $p, q$, if $x$ were to (a) consider inferring $p$ (or $q$ ) from $f(c$, $p, q$ ) for an appropriate amount of time, and (b) have no motivating reason against this inference, then $x$ would immediately infer $p$ (or $q$ ) from $f(c, p, q)$

and

(ii) for every proposition $p, q$, if $x$ were to (a) consider inferring $f(c, p, q)$ from $p$ and $q$ for an appropriate amount of time, and (b) have no motivating reason against this inference, then $x$ would immediately infer $f(c, p, q)$ from $p$ and $q .{ }^{7,8}$

Here, " $p$ " and " $q$ " are ordinary, first-order, objectual variables ranging over propositions. Clause (i) covers the elimination rule for conjunction and (ii) covers the introduction rule. Although I won't discuss the matter here, we may note that (D) can be modified so as to demand only (i) or (ii) for possession of AND, which would be tantamount to saying that possessing the concept merely requires a disposition to follow the elimination rule or introduction rule, respectively.

Another important variation adds a third condition alongside (i) and (ii), namely, that $x$ must not be "disposed toward" any other inference rule with respect to $c$ than the introduction and elimination rules of AND. Here, that $x$ is "disposed toward" the conjunction elimination rule with respect to $c$ simply amounts to (i) being true, and analogously for other inference rules.

Here and in the following three sections, I will clarify (D), argue that it indeed avoids all psychological exceptions discussed in the literature, and explain how it can be modified to accommodate various different views about concept possession. Like the theories of Paul Boghossian (2003) and Paul Horwich (2005), (D) is a dispositionalist version of inferentialism. Of course, inferentialist theories are

\footnotetext{
7 This theory is a refinement of my more inchoate suggestions in Båve (2015b: 26f, 2016: 14).

${ }^{8}$ I have heard more than one philosopher vent the suspicion that (D) is circular because its right-hand side presupposes that the person possesses the concept in question. It does, indeed, presuppose this, but this does not render (D) circular in any interesting sense. It would be circular if "AND" or some synonymous concept-designator had occurred in its right-hand side, but this clearly does not hold. I am not sure why (D) seems circular to some philosophers, but perhaps the impression gives way if one considers that the gist of (D) might as well be expressed by a sentence of the form, "AND = the concept $c$ such that $x$ possesses $c$ just in case ..." [cf. Peacocke (1992: 6-10)]. It is also important to note that (D) is not meant to define "possess", so it could well contain this word in its right-hand side without circularity.
} 
controversial $^{9}$ but their general viability is beyond the scope of this paper, which is rather about the particularly dispositionalist aspects of such theories.

The notion of inference is obviously central to (D). An inference, as I use the term, is a mental event, which may but need not result in a new belief. It can also result in the strengthening of one's belief (if one already believed the conclusion), or the kind of state resulting from an inference from a mere supposition (however exactly that kind of state should be characterized). Perhaps one can make an inference without believing or supposing the premises, but I will leave that open. I also leave open whether inference is (always) voluntary, conscious, subpersonal, or an act (rather than merely an event). I will say more about inference in Sect. 4, in response to a recent argument against inferentialism by Paul Boghossian.

By "immediately", I mean that the inference is not based on other beliefs. So, even if someone infers one proposition from another without considering any further proposition, this inference is still not immediate if it is causally dependent on previous inferences, as when an inference is a "shortcut" of previous, more complex inferences [cf. Peacocke (1992: 6) and the discussion in Sect. 4 below].

(D) handles the problem of error, I submit, simply because the relevant inferences are so basic, simple, and obvious that we simply do not make any "mistakes" here of the kind we might make when adding. It is important to note, though, that (D) is consistent with possessors of AND reasoning as illogically as one can imagine, as long as they satisfy (i) and (ii). A counter-example to (D) cannot consist in someone's making an inference (whether fallacious or not), but only in their not making an inference. The well-known empirical findings of human illogicality are thus no threat to (D). Also, on the final account I propose in Sect. 6, people can even possess AND at a time while failing to satisfy (i) or (ii), as long as this does not occur too often. ${ }^{10}$

Note how (D) differs from standard dispositionalist solutions to the problem of Error, which are attempts to salvage Kripke's idea that meaning plus amounts to a disposition to add, e.g., Martin and Heil (1998) and Fodor (1991). Those solutions involve controversial claims about the (highly contested) nature of dispositions,

\footnotetext{
${ }^{9}$ For overviews of the debate, see, e.g., Greenberg and Harman (2008), Whiting (2019), and Båve (2015a).

${ }^{10}$ With (D) in place, we can now also see how recognitional concepts like HORSE could be individuated along the lines of note 5. Let " $d$ " range over mental demonstratives, let HORSE be the perceptual similarity space related to horses, and let $p$ be the function taking one monadic predicative concept and one individual concept (including mental demonstratives) to propositions, so that $p$ (HORSE, CHISHOLM) is the proposition that Chisholm is a horse. Now, we can say,
}

$x$ possesses HORSE iff for some concept $c$, for all $d$, if $x$ had a perception in which $d$ falls within

HORSE, considered the proposition $f(c, d)$, and had no motivating reason against believing $f(c, d)$, then $x$ would believe $f(c, d)$.

We now need to explain what it is for a mental demonstrative to "fall within" a perceptual similarity space, but this should be possible. As with (D), it is difficult to see how anyone possessing HORSE could fail to satisfy this condition, except in cases of neural malfunction. As for the perceptual similarity space HORSE, note that we can use the word "horse" in defining it, without any resulting circularity in the concept possession above. What we cannot do, however, is to define it using the concept designator "HORSE". 
whereas mine, by appealing to undemanding cognitive tasks, can instead use simple counterfactuals.

\section{Considering inferences}

The precondition of "considering an inference" is probably the most tentative aspect of (D), so I will here try to clarify and defend it at some length. I think we need to set a constraint on this notion to the effect that anyone possessing and must be able to consider inferences in the relevant sense, including unsophisticated thinkers like small children. This means inter alia that we must not take this act to involve metaconceptual thought, i.e., thoughts about propositions (cf. Boghossian 2003).

This constraint clearly does not follow from (D). Nor is it needed to avoid triviality. My reason for setting it is rather that it is hard to see how anyone can have come to satisfy (i) or (ii) without having actually considered an inference, and then having somehow learnt to respond to this act by making the inference. Fortunately, we will see that the main independent motivation for positing this act type of considering will also motivate the claim that unsophisticated thinkers are indeed capable of performing it. (Note, however, that no analogous argument could be used to show that unsophisticated thinkers must be capable of having motivating reasons against an inference, so the constraint applies only to considering inferences.)

By including the precondition of considering inferences in (D), we can solve the problem of finitude. I will assume, as seems natural, that one can consider an inference only if one can entertain its premises and conclusion. But this immediately entails that, for propositions too complex to entertain, the instances of (i)a and (ii)a do not actually obtain, and so (D) does not entail that possessors of and actually make the relevant inferences. Thus, propositions too complex to entertain are not counterexamples to (D). (D) does require, of course, that in the closest possible world in which the antecedent of (i) holds of two highly complex propositions, so will the corresponding consequent. But this is as it should.

Note, again, the relatively uncontroversial ideas involved in this solution of the problem of finitude. By contrast, others have tried to solve the problem by positing "abstractions" of agents (Podlaskowski (2012)), or dispositions that are "infinitely projectible" (Martin and Heil (1998: §4)) or "composite" (Warren (forthcoming)). Similar ideas have been proposed by Blackburn (1984), Tennant (1997: §4.13.2), and Shogenji (1993).

Although these theorists agree with me that we need to appeal to "simpler tasks", their candidate tasks are all proposed as subtasks through which one is supposed to be able to give the sum of any two numbers. But, again, in order to possess PLUS (or mean plus by "+"), one need not be disposed to add very well at all, let alone be disposed to add any two numbers. One need not, for instance, have any idea of how to add double-digit numbers like 68 and 57 (e.g., by adding single digits, "carrying", and so on). By rejecting this Kripkean presupposition, we avoid stretching the notion of disposition beyond recognition, as these authors argubly do, and we avoid the unreasonably demanding conditions for possessing PLUS. These 
other theories also succumb to a "special" problem of finitude, described in Podlaskowski (2012: §4.2), which is exactly the problem of finitude for dispositionalist accounts of conjunction that I am here claiming to solve (see also Kusch (2006: 278f.) for further criticisms of Tennant).

Even if the precondition of considering solves the problem of finitude, we also need some independent motivation for positing this act type. To this end, note that, as Broome (2016: 632) emphasizes, people are not disposed simply to infer in accordance with rational inference rules, but only to the extent that they "take interest" in the conclusion. We don't (per impossibile) go around constantly forming new beliefs in propositions that follow via analytic inference rules from what we already believe. Some intermediary, triggering factor must be identified, and this is precisely what I take the act of considering an inference to be.

I propose that considering an inference is something close to the act of entertaining its premises and conclusion. This is suitably non-metaconceptual and thus an act that unsophisticated thinkers can perform. This act is presumably sensitive to what is relevant [cf. Gilbert Harman's "Maxims of Reasoning" (1986: 2) and Sperber and Wilson's Relevance Theory (1986)]. It also plausibly has as one of its functions to trigger inferences. These two characteristics are plausibly seen as connected, and illustrate the more general role that considering inferences plays in our cognitive system, particularly, its role in helping individuals to form relevant beliefs in response to real life situations. Although I think this gives us a firmer grasp of what we are trying to characterize, none of it needs to go into the conditions of possessing any concept. Such conditions need only involve the act of considering, not its connection with relevance, nor its function, nor its wider role in our cognitive lives.

I will remain neutral on how exactly "considering" should be defined, but I will mention some possibilities, which should clarify the matter further. Consider first the simpler case of coming to non-inferentially believe obvious propositions, as we may come to non-inferentially believe that $2=2$. Just as with inferences, we do not just categorically believe all obvious propositions. Rather, we are disposed to believe them upon consideration. Now, while considering in this sense could be the same as mere entertaining, we might instead have to relativize these acts to specific attitudes, distinguishing considering-for-belief, considering-for-desire, etc. To consider-for-belief the proposition that $p$ is similar to wondering whether $p$, or "asking oneself" whether $p$, as long as the latter can be taken as suitably undemanding and non-metaconceptual.

Returning now to "considering an inference", I think it plausible enough that it requires at least entertaining the conclusion and premises. The question is whether the entertaining of the premises and the entertaining of the conclusion must also be performed a certain way, and whether the acts must be connected somehow. I will leave these questions for another occasion, however, since I think I have said enough to motivate the positing of the act type of considering an inference.

Aside from solving the problem of finitude, the precondition of considering also helps us "shrink the distance" between input and output to such a minimum that there will be few or no causal intermediaries between them that may fail to be present, thus inhibiting the output. (This is consonant with our assumption that the 
act of considering an inference has the function of triggering inferences.) On the other extreme, we find behaviourist analyses, where, arguably, indefinitely many psychological factors can causally intervene between input and output (stimulus and response).

Although (D) thus avoids exceptions by "shrinking the distance" in this way, it is not thereby rendered trivial. For, firstly, the counterfactuals will only be true of analytic inferences (where an "analytic" inference is one which occurs in a (D)form individuation of some concept). Secondly, on the final theory defended in Sect. 6, these counterfactuals are sometimes false, even for analytic inferences, due to neural malfunction.

The appropriate amount of time in (D) means sufficiently long but not too long. We need the lower limit in order to allow possessors of AND who haven't inferred after a mere nanosecond's consideration. With this limit, we can also grant that they may fail to infer, even if they consider the inference and have no reason against it, if they get interrupted or distracted along the way (cf. Besson 2012: 67). The upper limit, by contrast, is needed to rule out thinkers as possessors of AND, namely, those who take too long considering before they infer. The boundaries of the "appropriate" amount of time are plausibly vague.

\section{Motivating reasons}

Having a motivating reason against an inference means having a motivating reason for not making it. Not making an inference is a so-called "negative action", but still an action, since it can be motivated in the same way as positive actions (see Bach 2010). The notion of a motivating reason [or "agent's reason" or what Hornsby (2008: 249) calls "B-type" reason] is well established in the philosophical literature [see, e.g., Dancy (2000) and Alvarez (2010) for overviews]. It is based on natural, intuitive uses of "reason", in which we can say that someone did something for a reason, although that reason might not be a good reason. It is just what made the person act the way she did.

The main point of qualifying the reasons spoken of in (D) as motivating is to distinguish them from normative reasons. A normative reason for something cannot be bad; it is by definition something that really provides justification (if only pro tanto). This latter is what we typically have in mind when we interpret, "The reason for believing in science is that it works". The notion of a motivating reason, by contrast, is non-normative, psychological and causal-explanatory. Some have taken motivating reasons to be psychological states, consisting of beliefs and desires (e.g., Smith 1994: 94ff.), but an analysis which better fits ordinary usage takes them to be propositions: the proposition $\mathrm{P}$ is a motivating reason for $x$ to $\phi$ iff $x$ 's believes $\mathrm{P}$ and this belief, in conjunction with other beliefs and desires of $x$, motivate $x$ to $\phi$. It seems, however, that the notion of a motivating reason is factive, i.e., that every motivating reason is true (cf. Unger 1975: 208). If that is so, then (D) requires a slightly different notion, which is like that of a motivating reason, minus factivity, and this is in fact the notion I just defined. 
However natural, the notion of motivating reason is controversial. Opponents insist that reasons cannot be mental and cannot be non-normative [see, e.g., Williamson (forthcoming)]. This seems to me purely terminological, however. It is clear that we do speak of bad reasons in ordinary language, and also of people's having reasons as being psychologically causal-explanatory. Note that not any psychological factor preventing someone from doing something amounts to there being a motivating reason against their doing it. If it were, (D) would be at risk of trivialization. Having a motivating reason motivates the person to act in the typical and distinctive way of belief, desires, and intentions. Although the notion of a motivating reason is contested, I think it should be clear enough what I am after here, and that any party to the debate about reasons can find their own favoured way of saying what I am using "having a motivating reason" to say (perhaps using "apparent reason" or "taking so and so to be a reason", or even by eschewing the notion of reason and speaking merely of beliefs motivating one not to infer). However exactly one wishes to express the (b)-clauses in (D), it is clear that we are after some psychological, causal, non-normative notion, rather than the abstract and normative notion of objective reason.

Wedgwood (2007) has argued that concepts cannot be individuated in wholly descriptive terms, because the dispositions constituting the possession of a concept can only be described using the normative notion of a defeater, where a defeater is a good reason to suspend judgment. But his account thereby entails, wrongly, that a person who fails to infer in the required way for a bad reason ipso facto does not possess the concept (cf. Rey 2007: §3.4). (Therefore, I think normativists like Wedgwood, who want to claim that concepts cannot be individuated in wholly descriptive terms, had better reject the very idea that concepts can be individuated by their possession conditions, and say instead that they are individuated by what normative principles they satisfy.)

One can have a reason against an inference in two ways: one may have a reason to reject the conclusion, or one can have some reason against the inference proper (note that the former is not a reason against inferring if the premises are merely supposed, rather than believed). The latter can consist in the belief either that the inference is invalid or unreliable, or that one is unreliable (momentarily or permanently) as far as the relevant kind of inference is concerned (perhaps due to confusion, inebriation, etc.). These distinctions between kinds of defeaters are commonplace in epistemology (see, e.g., Pollock 1974: §3.3).

The precondition of "having no motivating reason against" is meant to take care of cases of

(1) people with "deviant" logics/theories,

(2) people failing to infer something simply because they disbelieve the conclusion (in which they may instead come to disbelieve one of the premises, as in Harman's examples of "reasoned change in view"),

(3) people who think they are momentarily unreliable with respect to the relevant kind of inference, and

(4) people convinced of "scepticism about reason" (supposing this is possible at all). 
I think this should be obvious enough for each of (1)-(4), but we may briefly look at how the clause helps with case (1), for illustration. Williamson has argued at length that a logician could hold a deviant theory, due to which he takes some sentences of the form "Every $F$ is $F$ " to be untrue, and hence refuses to accept it (or believe the proposition it expresses). But someone's holding a deviant theory and consequently failing to accept, believe, or infer something is of course a case in which they have a motivating reason against doing so. Hence, such cases are not counterexamples to (D).

One might worry that the precondition of not having a motivating reason against the inference makes the right-hand side of (D) too weak, rendering (i) or (ii) true of concepts other than AND. For instance, the concept oR may seem to satisfy (i), since we always have a reason against inferring $\langle p\rangle$ from $\langle p$ or $q\rangle$, which may seem to make (i) vacuously true. ${ }^{11} \mathrm{We}$ can grant that there is always and necessarily an objective reason against this inference involving or, but this has no bearing on (i), which concerns motivating reasons, in the sense explained. And it is clearly possible to lack a motivating reason against the inference. In fact, most people do most of the time, since they usually haven't even considered the matter.

What about someone who does have a motivating reason against inferring $\langle p\rangle$ from $\langle p$ or $q\rangle$ ? This case is unproblematic, too, since (i) is a counterfactual, rather than a material conditional, and is thus not rendered true by the falsity of its antecedent. On the standard Lewis-Stalnaker semantics, whether (i) is true rather depends on whether the consequent is true in the closest possible world in which the antecedent is true. The antecedent, moreover, is clearly metaphysically possible. This is so even for someone who is so constituted that, whenever he considers the inference, a motivating reason against it pops up. For even if this connection holds of someone, it cannot hold of metaphysical necessity. And since the antecedent is possible, the counterfactual can be false. Thus, neither of these two considerations about the concept oR shows that the precondition of not having a motivating reason against makes (D)'s possession condition too weak.

Let me close this section by briefly considering such "dysfunctional states" as confusion, inattention, etc. These alleged counterexamples have not been elaborated in the literature, but have rather just been listed without further comment in order to illustrate the "many and disparate" exceptions to dispositionalist analyses. Although these cases seem to present problems for Kripke's Dispositionalism, which involves demanding dispositions, it is unclear whether they amount to anything over and above the Problem of Error, simply providing various explanations of why someone may make relevant errors.

In any case, there are at least three reasons to think they do not pose a problem for (D). Firstly, one may take the inferences in (D) to be so simple that, no matter how drunk, tired, or confused, if one has been sober enough to consider making it, one will be sober enough to make it, at least barring neural malfunctioning. Secondly, one could take these confused states to be states in which one often fails

\footnotetext{
11 Thanks to Peter Pagin for raising this worry about an earlier draft of this paper, in which it wasn't as clear that the notion of reason I was employing was that of a motivating reason.
} 
to consider obvious inferences. In that case, however, they are clearly no problem for (D). Thirdly, these dysfunctional states can be seen as states in which we suffer neural malfunction more often than otherwise. But if so, then the worry about confused states will be answered by my treatment of neural malfunction, given in Sect. 6. (One might worry that it has now become unclear whether drunkenness and the like should be classified as a psychological factor or not. But I don't think this is a problem: it could conceivably be defined both in (partly) psychological terms and in wholly non-psychological terms. The above points seem to stand in either case.)

\section{5 (D)'s position in dialectical space}

Boghossian (2014) has levelled an argument against inferentialism (and his former self), based on considerations about the nature of inference. This argument clearly also targets (D), so we had better ensure it does not refute it. He argues that inference must be taken to essentially involve the person's taking the premises to justify the conclusion, and further that this "taking" must be seen as an intentional state. (Note that while inference is obviously intentional in that it relates intentional states, the interesting question is whether the relation itself must be understood in intentional terms.) He then infers from this claim to the falsity of inferentialism. I think this inference may well be correct, but that the premise is insufficiently motivated.

Against the view that inference is merely a matter of beliefs causing other beliefs, Boghossian notes that there are cases of beliefs-causing-beliefs that are not inferences. Even so, it may still be possible to define inference as a process of beliefs-causing-beliefs satisfying some further condition, which does not involve intentional states. And there might of course be non-intentional accounts of inference that don't take them to be a matter of beliefs causing beliefs. (Responding to Boghossian, Broome 2014 argues that there is.) Also, there might be several legitimate notions of inference, some of which make it an intentional relation and some of which make it non-intentional. The question would then be why the latter couldn't be used for the purposes of Inferentialism or Semantic Dispositionalism.

If unsophisticated thinkers like small children can infer, then inference simply can't satisfy Boghossian's "taking condition", since this entails an ability for metaconceptual thought and some concept of epistemic justification that these thinkers do not have. Even if we accept Boghossian's condition and conclude that small children cannot infer, we must still arguably hold that they undergo some simpler, inference-like type of process. But then, we could perhaps substitute inference in (D) for this simpler process.

Let us now turn to Peacocke's (1992) theory of concepts, and the ways in which I hold (D) to be preferable. Peacocke takes the possession conditions of logical concepts like conjunction to be that one find the relevant inferences primitively compelling. That a person finds an inference primitively compelling means that "(1) he finds them compelling; (2) he does not find them compelling because he has inferred them from other premises and/or principles; and (3) for possession of the 
concept $C$ in question (here conjunction) he does not need to take the correctness of the transitions as answerable to anything else" (1992: 6).

But on its most natural interpretation, "finding a transition compelling" means having a propositional attitude about "transitions" to the effect that they are "compelling". This involves sophisticated metaconceptual thought, as well as a sophisticated epistemic or cognitive concept of being compelling, which we cannot plausibly take to be a precondition of possessing AND (think of the children!). Perhaps Peacocke wants to ultimately explain this seeming appeal to a propositional attitude in non-intentional terms, but until we have any idea of how to do so, we are stuck with an unacceptable account of logical concepts. My view is, of course, that (D) provides precisely the kind of non-intentional and undemanding condition that we are after.

Although I reject Peacocke's theory, I agree that what constitutes concept possession is primitive and immediate in roughly the way he indicates. But this, I think, is accommodated by (i) and (ii) as they stand. This is so, firstly, because of the qualifier, "immediately", which is defined as a matter of not being causally dependent on other, previous inferences or beliefs. (D) also captures a kind of immediacy simply by its paucity of stimulus conditions: nothing more than the satisfaction of (a) and (b) is necessary for the person to infer. This is perhaps easier to see if one considers that primitiveness and immediacy are negative notions, primitiveness consisting in a lack of a certain kind of grounding and immediacy consisting in a lack of intermediaries.

Peacocke also takes possession of AND to require that one finds the inferences primitively compelling "because they are of [the relevant] forms" (ibid.). Although (D) does not explicitly mention forms, it still entails a kind of minimal sensitivity to form simply in virtue of its mention of the propositions $p$ and $q$ and the corresponding $f(c, p, q)$. To demand more than this minimal sensitivity, e.g., thoughts about forms, would again be to over-intellectualize. In conclusion, (D) seems capable of accommodating many of the insights behind Peacocke's possession conditions, and yet avoids the objection from over-intellectualization, by stating a condition that does not involve any propositional attitude about inferences, to the effect that they are compelling.

Finally, let me briefly comment on Besson's (2012) discussion about whether dispositions to disbelieve should be required for possessing logical concepts, e.g., whether, to possess AND, one must be disposed to disbelieve a conjunction when one disbelieves one of the conjuncts (here, I use "disbelieve" in the sense in which it is closely tied to belief in negation, rather than in the sense of suspended judgment).

(D) does not set any such requirement, but could easily be modified so as to rectify this, if needed. Such a modification would mean giving a bilateral account (see, e.g., Rumfitt 2000). This worry is thus no threat against Semantic Dispositionalism as such, but only against its unilateral variants. In order to give a bilateral account along the lines of (D), we need to posit an act analogous to inference, yet involving disbelief rather than merely belief. But this posit seems reasonable, and something which adherents of bilateralism are arguably committed to anyway. 


\section{A dispositionalist theory without exceptions?}

If (D) indeed avoids all psychological kinds of exceptions, we are better equipped to deal with the remaining one, involving neural malfunction. Before laying out my own proposal, let me mention a more obvious one, namely, to simply add to the preconditions in (D) that no neural malfunctioning (noise, etc.) is taking place. This proposal faces difficulties very similar to those afflicting dispositionalist theories with "ceteris paribus" hedges. Adding this precondition immediately raises the question of what neural malfunction is, and it is hard to see how to answer this question without trivializing the account. Something is a state of malfunction only relative to some proper functioning. In the present context, proper functioning consists in the satisfaction of (i) and (ii). But if malfunction is so defined that a case of malfunction comes out as one in which (i) or (ii) is false, then the "no malfunction" condition will trivialize the account. For this reason, I think, a theory that avoids counterexamples from neural malfunction must not mention them as such, i.e., it should not use the notion of neural malfunction.

I will deal with neural exceptions by taking it to be necessary and sufficient for possessing AND that one satisfies (i) and (ii) sufficiently often (during a given interval). A similar hedge is used by Manley and Wasserman (2008) and Cheng (2010). However, the former do it for very different purposes, and I'll argue below that my proposal differs markedly and advantageously from Cheng's. If I am right that (D) has no psychological exceptions, it follows that the only times at which (i) and (ii) will not be true of a person who possesses AND will be times at which there is neural malfunction. But it is nowhere asserted that these exceptions are cases of neural malfunction. Therefore, we are under no obligation to define this notion, and hence at no risk of trivializing the account in the way explained above. We can define, "being true sufficiently often during an interval $I$ " as "being true during a sufficiently large (possibly scattered) portion of $I$ ", and we can define the simpler "true during $I$ " as "true at every point of time in $I$ ".

Turning now to a rather different consideration, which will prove relevant for the final proposal, consider the widely shared intuition that one cannot be in such mental states as belief, desire, understanding something, etc., for a mere split second. I propose that the same holds for concept possession, and that this fact can be accommodated by saying that in order to possess a concept at a time, that time must be part of a longer interval, throughout which the relevant counterfactuals must hold sufficiently often. This proposal thus handles at once the problem of neural malfunction and the intuition about concept possession as non-instantaneous. Thus, the final proposal will read, 
$\left(\mathrm{D}^{\prime}\right) \quad x$ possesses AND at $t$ just in case, for some concept $c$, and all propositions $p, q$, there is a sufficiently long interval $I(t \in I)$, such that it holds sufficiently often during $I$ that (i) and (ii). ${ }^{12,13}$

Here, the quantifiers bind the variables " $p$ " and " $q$ " in (i) and (ii), which are as in (D).

It is naturally a vague matter how much is "sufficient". Thus, I take concept possession to be vague along the same dimension, and I take it to be a recommending feature of $\left(\mathrm{D}^{\prime}\right)$ that it accommodates our intuition that concept possession is indeed vague in this way. Here is a way of bringing this intuition out. Assuming that possession of AND hinges on satisfaction of (i) and (ii) at all, it seems clear that someone who never satisfies them determinately does not possess the concept, and someone who always satisfies them determinately does. But, intuitively, there will also be intermediary cases, in which it will be indeterminate whether the person possesses the concept.

Consider someone who has some neural configuration which would normally make them satisfy (i) and (ii). If some other neural, non-psychological factor "blocks the disposition" too often, i.e., if it prevents the person from satisfying (i) and/or (ii) too often, then she does not possess the concept. This is in sharp contrast to the case in which the blocking factor is psychological, e.g., belief in some deviant logic. One can possess a concept even if one never makes analytic inferences that one considers, if the inhibitions are psychological, e.g., belief in some deviant logic. In cases of non-psychological blockers, by contrast, there is just "something wrong with" the person; there is a basic deficiency due to which he does not possess the concept. Someone's belief in a deviant logic may also be deficient in the sense that it is irrational, but this is not the kind of basic deficiency that entails failure to possess the concept.

I have spoken here of neural factors blocking so and so, but I should emphasize that I take the exact neural structure of a person's brain to be inessential to concept possession. As long as one satisfies the right-hand side of $\left(\mathrm{D}^{\prime}\right)$, it does not matter if one has a discrete neural structure underlying one's satisfaction of (i) and (ii) and if the occasional blocking factor is also discrete or whether it is part of the underlying structure, and so on. All that matters is that one satisfies (i) and (ii) sufficiently often.

The condition in $\left(\mathrm{D}^{\prime}\right)$ could be further complicated to accommodate certain other intuitions. Perhaps it should be required that the intervals during which (i) and (ii) are never true are not too long. Also, perhaps we can be more tolerant of long periods of malfunction (i.e., when (i) and (ii) are not true of a person) when they are

\footnotetext{
${ }^{12}$ There are some obvious variations here, e.g., having " $S O^{I}((\mathrm{i})) \& S O^{I}((\mathrm{ii}))$ " instead of " $S O^{I}((\mathrm{i}) \&($ ii $))$ ", but I will not discuss such niceties here. It may well be indeterminate which variant is correct.

13 This theory may seem similar to the view, advanced by Cheng (2011), that meaning-attributions should be seen as habituals or generics, following Michael Fara's similar treatment of disposition attributions (2005). Both views suffer from the problem that they defer the solution of the puzzles about attributions of meaning or dispositions to the study of habituals or generics, which are notoriously difficult to characterize semantically. My theory has no such problem, since it merely states a simple (albeit vague) boundary of "sufficiently often" and does not defer to the study of some poorly understood semantic phenomenon.
} 
explicable, or explicable in a certain way. For instance, perhaps we can be more generous toward someone with rather long intervals of not satisfying (i) and (ii), if that failure is explained by the intake of drugs or some other identifiable cause. Thus, the above definition of "sufficiently often" could be replaced by one that assigns different weights to periods of malfunction, depending, e.g., on their causes. That seems reasonable to me, but I will leave these niceties for another occasion.

Now, one might wonder, if we allow this condition of "sufficiently often", couldn't we do away with at least one of the preconditions in (D)? No. If the "having no reason against" condition were omitted, people with a "deviant logic", who never infer in accordance with an analytic rule would wrongly count as not possessing the concept. And without the "considering" condition, people would fail to satisfy the counterfactuals almost all of the time, making it impossible to set a reasonable limit to "sufficiently often". The "sufficiently often" hedge also does not allow us to require more demanding dispositions, like the disposition to add, for even very poor adders, who mostly gives non-sums for given adding tasks, may possess the concept PLUS.

Finally, I want to compare $\left(\mathrm{D}^{\prime}\right)$ with a recent claim made by Cheng (2010: $\left.\S 4\right)$, which is that one has a "rule-following disposition" only if any intrinsic and/or permanent antidotes be activated "only occasionally", i.e., only if such inhibiting factors be absent sufficiently often. While this may superficially seem similar to $\left(\mathrm{D}^{\prime}\right)$, it is in fact very different. Cheng's proposal is intended as a defence of Martin and Heil's realist version of Kripke's Dispositionalism with respect to plus. But I am of course not defending that theory, since I take it to set too demanding a condition for concept possession. Secondly, Cheng's account explicitly mentions antidotes $a s$ such, and thus runs the risk of trivialization.

More importantly, my condition of "sufficiently often" is intended to take care only of neural malfunctioning and not, as in Cheng's account, of any factor, psychological or not, that may prevent someone from adding correctly. Cheng's claim has precisely the implausible consequence I took pains to avoid, that "alternative logicians", who permanently fail to infer in accordance with analytic inference rules, come out as not possessing the relevant concept. We were able to avoid this consequence (while simultaneously steering clear of Peacocke's overintellectualization) by setting conditions which are both suitably undemanding and whose only exceptions are cases of neural malfunctioning. The last condition is crucial, for it seems that a concept possessor could always have some psychological mechanism constantly preventing them from inferring in accordance with analytic rules. To see how $\left(\mathrm{D}^{\prime}\right)$ differs from and improves upon Cheng's view, it is thus crucial to take the whole of $\left(\mathrm{D}^{\prime}\right)$ into account, including the details it inherits from (D) and their motivation. ${ }^{14}$

\footnotetext{
14 Interestingly, Cheng also comments on the vagueness of "sufficiently". However, he suggests that it may be a problem for his defence, saying: "One may wonder how the question whether a subject $\mathrm{S}$ follows rule A or rule B can be settled on a realistic dispositionalist account that invokes such vague predicates. Doesn't invoking these vague phrases imply that the answer to the question whether S follows rule A or rule B will remain vague too? And doesn't this result confirm Kripke's scepticism after all?" (2010: 215).
} 
While $\left(\mathrm{D}^{\prime}\right)$ may turn out to face novel counterexamples, it does seem to avoid those discussed in the literature. Philosophers of language have attached great principal importance both to "the very idea" of Semantic Dispositionalism and to its alleged exceptions. But if these exceptions can be avoided, as I have argued, then Semantic Dispositionalism deserves renewed attention. Also, if new counterexamples are found, they are likely to reveal more interesting failings of "the very idea".

Open Access This article is distributed under the terms of the Creative Commons Attribution 4.0 International License (http://creativecommons.org/licenses/by/4.0/), which permits unrestricted use, distribution, and reproduction in any medium, provided you give appropriate credit to the original author(s) and the source, provide a link to the Creative Commons license, and indicate if changes were made.

\section{References}

Alvarez, M. (2010). Kinds of reasons: An essay on the philosophy of action. Oxford: OUP.

Azzouni, J. (2017). The rule-following paradox and its implications for metaphysics (Vol. 382). Dordrecht: Springer.

Bach, K. (2010). Refraining, omitting, and negative acts. In T. O'Commor \& C. Sandis (Eds.), Companion to the philosophy of action (pp. 50-57). Oxford: Blackwell.

Båve, A. (2015a). Conceptual role semantics. In D. Pritchard (Ed.), Oxford bibliographies online: Philosophy. Oxford: Oxford University Press.

Båve, A. (2015b). A deflationist error theory of properties. Dialectica, 69, 23-59.

Båve, A. (2016). Self-consciousness and reductive functionalism. The Philosophical Quarterly, 67(266), $1-21$.

Båve, A. (forthcoming). Concept designation. American Philosophical Quarterly.

Besson, C. (2012). Logical knowledge and ordinary reasoning. Philosophical Studies, 158, 59-82.

Blackburn, S. (1984). The individual strikes back. Synthese, 58, 281-302.

Boghossian, P. (1989). The rule-following considerations. Mind, 98, 507-549.

Boghossian, P. (2003). Blind reasoning. Proceedings of the Aristotelian Society, 77, 225-248.

Boghossian, P. (2014). What is inference? Philosophical Studies, 169, 1-18.

Broome, J. (2014). Comments on Boghossian. Philosophical Studies, 169, 19-25.

Broome, J. (2016). Synchronic requirements and diachronic permissions. Canadian Journal of Philosophy, 45, 630-646.

Cheng, K.-Y. (2009). Semantic dispositionalism, idealization, and ceteris paribus clauses. Minds and Machines, 19, 407-419.

Cheng, K.-Y. (2010). Intrinsic finks and attributions of rule-following dispositions. Grazer Philosophische Studien, 80, 209-220.

Cheng, K.-Y. (2011). A new look at the problem of rule-following: A generic perspective. Philosophical Studies, 155, 1-21.

Choi, S. (2008). Dispositional properties and counterfactual conditionals. Mind, 117, 795-841.

Choi, S., \& Fara, M. (2018). Dispositions. In Zalta (Ed.), The stanford encyclopedia of philosophy. https:// plato.stanford.edu/archives/fall2018/entries/dispositions.

Crane, T. (Ed.). (1996). Dispositions: A debate. London: Routledge.

Dancy, J. (2000). Practical reality. Oxford: Clarendon Press.

Footnote 14 continued

But there obviously are numerous indeterminacies related to semantic phenomena, which should be accommodated by an adequate theory. One of them, as I argued above, concerns the extent to which counterfactuals like (i) and (ii) must be satisfied for someone to possess a concept, and this indeterminacy is accommodated by $\left(\mathrm{D}^{\prime}\right)$ due to the vagueness of "sufficiently often" as it occurs there. In this case, therefore, the occurrence of a vague predicate is not a deficiency, but a means of satisfying a condition of adequacy. 
Davis, W. (2003). Meaning, expression, and thought. Cambridge: CUP.

Fara, M. (2005). Dispositions and habituals. Nous, 39, 43-82.

Fodor, J. (1983). The modularity of the mind. Cambridge, MA: MIT Press.

Fodor, J. (1990). A theory of content and other essays. Cambridge, MA.: MIT Press.

Fodor, J. (1991). You can fool some of the people all of the time, everything else being equal: Hedged laws and psychological explanation. Mind, 100, 19-34.

Gauker, C. (2011). Words and images: An essay on the origin of ideas. Oxford: OUP.

Glüer, K., \& Wikforss, А. (2009). Against content normativity. Mind, 118, 31-70.

Glüer, K., \& Wikforss, A. (2018). The normativity of meaning and content. In E. N. Zalta (Ed.), The Stanford encyclopedia of philosophy. https://plato.stanford.edu/archives/spr2018/entries/meaningnormativity.

Greenberg, M., \& Harman, G. (2008). Conceptual role semantics. In E. Lepore \& B. Smith (Eds.), The Oxford handbook of philosophy of language (pp. 296-322). Oxford: Oxford University Press.

Gundersen, L. (2002). In defence of the conditional account of dispositions. Synthese, 130, 389-411.

Harman, G. (1986). Change in view: Principles of reasoning. Cambridge, MA.: MIT Press.

Handfield, T., \& Bird, A. (2008). Dispositions, rules, and finks. Philosophical Studies, 140, 285-298.

Heil, J. (2003). From an ontological point of view. Oxford: Clarendon Press.

Hornsby, J. (2008). A disjunctivist conception of acting for reasons. In A. Haddock \& F. Macpherson (Eds.), Disjunctivism: Perception, action, knowledge. Oxford: OUP.

Horwich, P. (1998). Meaning. Oxford: Clarendon Press.

Horwich, P. (2005). Reflections on meaning. Oxford: Clarendon Press.

Kripke, S. (1982). Wittgenstein on rules and private language. Cambridge, MA: Harvard University Press.

Kusch, M. (2005). Fodor v. Kripke: Semantic dispositionalism, idealization and ceteris paribus clauses. Analysis, 65, 156-163.

Kusch, M. (2006). A sceptical guide to meaning and rules: Defending Kripke's Wittgenstein. Montreal: McGill-Queen's University Press.

Lewis, D. (1997). Finkish dispositions. The Philosophical Quarterly, 47, 143-158.

Manley, D., \& Wasserman, R. (2008). On linking dispositions and conditionals. Mind, 117, 59-84.

Martin, C., \& Heil, J. (1998). Rules and powers. Philosophical Perspectives, 12, 283-312. (Language, Mind, and Ontology).

Miller, A. (1997). Philosophy of language. Oxford: Oxford University Press.

Mumford, S. (1998). Dispositions. Oxford: OUP.

Peacocke, C. (1992). A study of concepts. Cambridge, MA: MIT Press.

Pettit, P. (1999). A theory of normal and ideal conditions. Philosophical Studies, 96, 21-44.

Pietroski, P., \& Rey, G. (1995). When other things aren't equal: Saving Ceteris Paribus laws from vacuity. The British Journal for the Philosophy of Science, 46, 81-110.

Podlaskowski, A. (2012). Simple tasks, abstractions, and semantic dispositionalism. Dialectica, 66, 453-470.

Podlaskowski, A., \& Jones, N. (2012). Idealizing, abstracting, and semantic dispositionalism. European Journal of Philosophy, 20, 166-178.

Pollock, J. (1974). Knowledge and justification. Princeton University Press: Princeton.

Reutlinger, A., Schurz, G., \& Hüttemann, A. (2019). Ceteris Paribus laws. In Zalta (Ed.), The stanford encyclopedia of philosophy. https://plato.stanford.edu/archives/spr2019/entries/ceteris-paribus.

Rey, G. (2007). Resisting normativism in psychology. In B. McLaughlin \& J. Cohen (Eds.), Contemporary debates in philosophy of mind (pp. 69-84). Oxford: Blackwell.

Rumfitt, I. (2000). 'Yes' and 'no'. Mind, 109, 781-824.

Shogenji, T. (1993). Modest scepticism about rule-following. Australasian Journal of Philosophy, 71, 486-500.

Smith, M. (1994). The moral problem. Oxford: Blackwell.

Sperber, D., \& Wilson, D. (1986). Relevance: Communication and cognition. Cambridge, MA: Harvard University Press.

Steinberg, J. (2010). Dispositions and subjunctives. Philosophical Studies, 148, 323-341.

Tennant, N. (1997). The taming of the true. New York: Clarendon Press.

Unger, P. (1975). Ignorance: A case for scepticism. Oxford: Clarendon Press.

Vetter, B. (2014). Dispositions without conditionals. Mind, 123, 129-156.

Warren, J. (forthcoming). Killing Kripkenstein's monster. Noûs.

Wedgwood, R. (2007). Normativism defended. In B. McLaughlin \& J. Cohen (Eds.), Contemporary debates in philosophy of mind (pp. 85-101). Oxford: Blackwell. 
Whiting, D. (2019). Conceptual role semantics. In J. Fieser \& B. Dowden (Eds.), The internet encyclopedia of philosophy. Spring. https://www.iep.utm.edu/.

Williamson, T. (2007). The philosophy of philosophy. Oxford: Blackwell.

Williamson, T. (forthcoming). Acting on knowledge. In J.A. Carter, E. Gordon, \& B. Jarvis (Eds.), Knowledge-first. OUP: Oxford.

Publisher's Note Springer Nature remains neutral with regard to jurisdictional claims in published maps and institutional affiliations. 